\title{
Coronary Artery Number of Diseased Vessels (Excludes Left Main Disease)
}

National Cancer Institute

\section{Source}

National Cancer Institute. Coronary Artery Number of Diseased Vessels (Excludes Left

Main Disease). NCI Thesaurus. Code C80426.

The number of coronary arteries that have at least 70\% luminal obstruction. 